\title{
Status of ISS Water Management and Recovery
}

\author{
Layne Carter ${ }^{1}$ \\ NASA Marshall Space Flight Center, Huntsville, AL 35812 \\ Barry Tobias ${ }^{2}$ \\ NASA Johnson Space Center, Houston, TX 77058 \\ Nicole Orozco ${ }^{3}$ \\ The Boeing Company, Houston, TX 77058
}

\begin{abstract}
Water management on ISS is responsible for the provision of water to the crew for drinking water, food preparation, and hygiene, to the Oxygen Generation System (OGS) for oxygen production via electrolysis, to the Waste \& Hygiene Compartment (WHC) for flush water, and for experiments on ISS. This paper summarizes water management activities on the ISS US Segment, and provides a status of the performance and issues related to the operation of the Water Processor Assembly (WPA) and Urine Processor Assembly (UPA). This paper summarizes the on-orbit status as of June 2012, and describes the technical challenges encountered and lessons learned over the past year.
\end{abstract}

\section{Introduction}

$\mathrm{T}$ he International Space Station (ISS) Water Recovery and Management (WRM) System insures availability of potable water for crew drinking and hygiene, oxygen generation, urinal flush water, and payloads as required. To support this function, waste water is collected in the form of crew urine, humidity condensate, and Sabatier product water, and subsequently processed by the Water Recovery System (WRS) to potable water. This product water is provided to the potable bus for the various users, and is stored in water bags for future use when the potable bus needs supplementing. The WRS is comprised of the Urine Processor Assembly (UPA) and Water Processor Assembly (WPA), which are located in two ISPR racks, named WRS\#1 and WRS\#2. This hardware was delivered to ISS on STS-126 on November 14, 2008 and initially installed in the US Lab module. On February 18, 2010, the racks were transferred to their permanent home in the Node 3 module.

\section{Description of the ISS Water Recovery and Management System}

The ISS WRM provides the capability to receive the waste water on ISS (crew urine, humidity condensate, and Sabatier product water), process the waste water to potable standards via the WRS, and distribute potable water to users on the potable bus. A conceptual schematic of the WRM is provided in Figure 1. The waste water bus receives humidity condensate from the Common Cabin Air Assemblies (CCAAs) on ISS, which condenses water vapor and other condensable contaminants and delivers the condensate to the bus via a water separator. In addition, waste water is also received from the Carbon Dioxide Reduction System. This hardware uses Sabatier technology to produce water from carbon dioxide (from the Carbon Dioxide Removal Assembly (CDRA)) and hydrogen (from the electrolysis process in the Oxygen Generation System). Waste water is typically delivered to the WPA Waste Tank, though the Condensate Tank located in the US Laboratory Module is available in the event the WPA Waste Tank is

${ }_{1}^{1}$ Life Support Design Team Lead, NASA MSFC ES62.
2 ISS ECLSS Officer, NASA JSC DI52 Mission Operations Directorate.
${ }^{3}$ ISS Water Recovery and Management Team Lead, The Boeing Company.

1

American Institute of Aeronautics and Astronautics 
disconnected from the waste bus. If this is required, the crew must manually connect the Condensate Tank to the waste water bus. Once the WPA Waste Tank is online again, the crew will disconnect the Condensate Tank from the waste water bus. Condensate collected in this scenario must subsequently be offloaded into a Contingency Water Container (CWC). The CWC can then be emptied into the WPA waste tank via a pump, transferred to the Russian Segment for processing by the Russian Condensate Processor (referred to as the SRV-K) or vented overboard (though venting is highly discouraged due to the loss of water consumables and use of propellant required to maneuver the ISS into an acceptable attitude).

Crew urine is collected in the Waste \& Hygiene Compartment (WHC), which includes a Russian Urinal (referred to as the ACY) integrated for operation in the US Segment. To maintain chemical and microbial control of the urine and hardware, the urine is treated with chemicals and flush water. The pretreated urine is then delivered to the Urine Processor Assembly (UPA) for subsequent processing. The UPA produces urine distillate, which is pumped directly to the WPA Waste Water Tank, where it is combined with the humidity condensate from the cabin and Sabatier product water, and subsequently processed by the WPA. A detailed description of the UPA and WPA treatment process is provided in Section III.

After the waste water is processed by the WRS, it is delivered to the potable bus. The potable bus is maintained at a pressure of approximately 230 to $280 \mathrm{kPa}$ (19 to $26.5 \mathrm{psig}$ ) so that water is available on demand from the various users. Users of potable water on the bus include the Oxygen Generation System (OGS), the WHC (for flush water), the Potable Water Dispenser (PWD) for crew consumption, and Payloads.

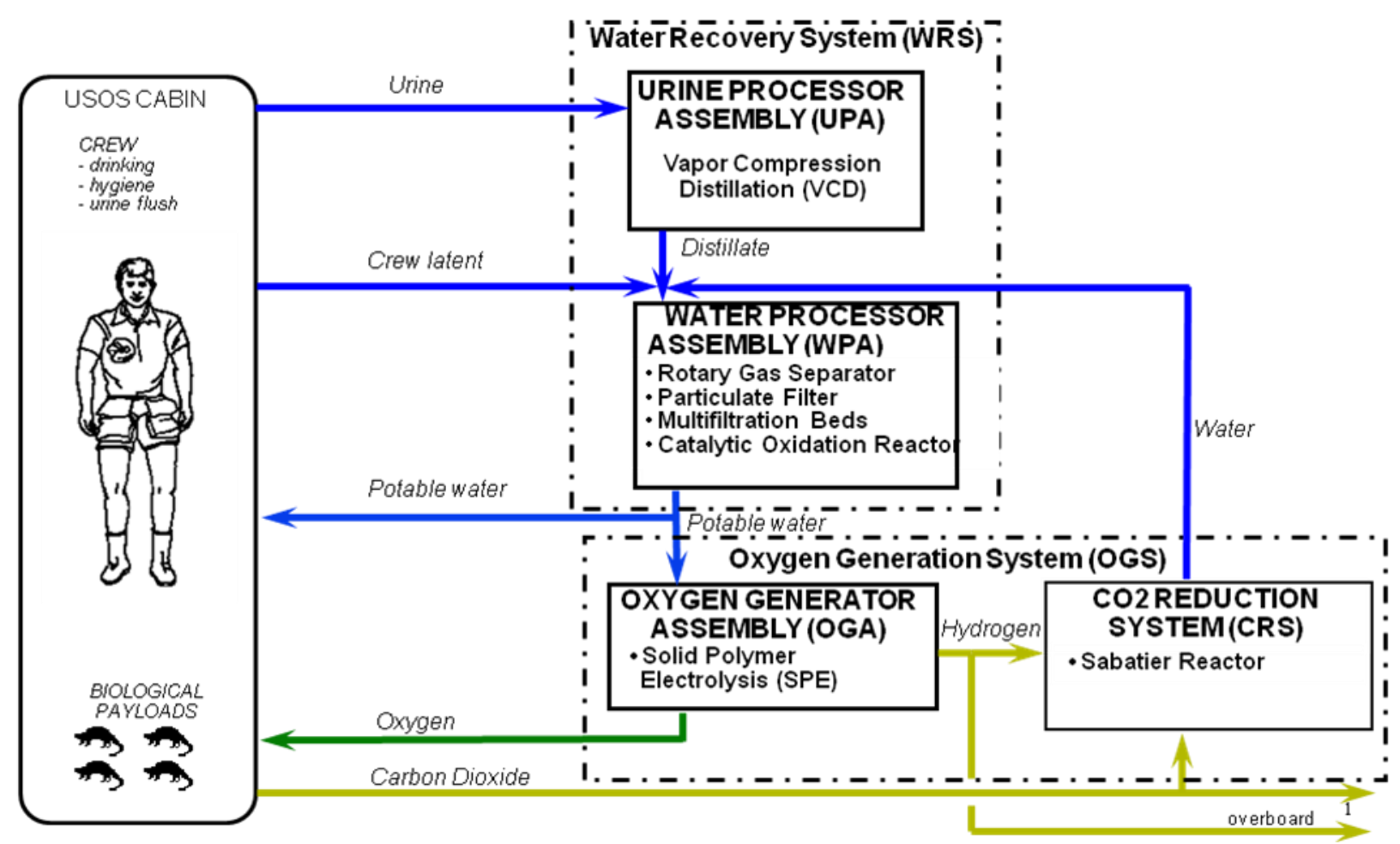

Figure 1. Water Recovery and Management Architecture for the ISS US Segment

\section{Description of the ISS Water Recovery System}

The layout of the two WRS racks is shown in Figure 2, along with the OGS. The WPA is packaged in WRS Rack \#1 and partially in WRS Rack \#2, linked by process water lines running between the two racks. The remaining portion of WRS Rack \#2 houses the UPA.

The following section provides a description of the WRS, current operational status, and describes issues and lessons learned during the past year. For the prior years' status, see references 1-4. 


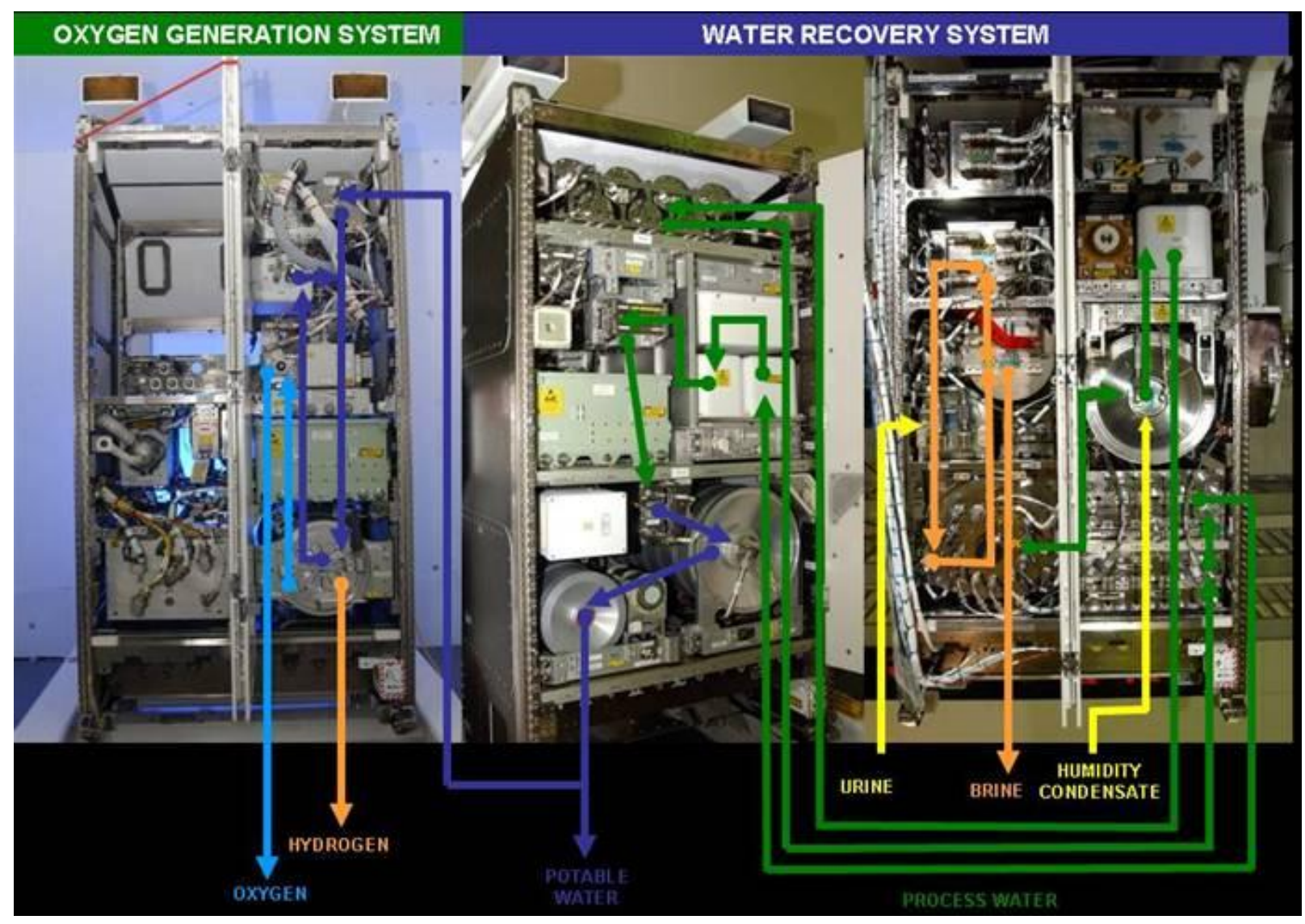

Figure 2. International Space Station Regenerative ECLSS Racks

\section{A. Water Processor Assembly Overview}

A simplified schematic of the WPA is provided in Figure 3. Wastewater delivered to the WPA includes condensate from the Temperature and Humidity Control System and distillate from the UPA. This wastewater is temporarily stored in the Waste Water Tank Orbital Replacement Unit (ORU). The Waste Water Tank includes a bellows that maintains a pressure of approximately $5.2-15.5 \mathrm{kPa}(0.75$ to $2.25 \mathrm{psig})$ over the tank cycle, which serves to push water and gas into the Mostly Liquid Separator (MLS). Gas is removed from the wastewater by the MLS (part of the Pump/Separator ORU), and passes through the Separator Filter ORU where odor-causing contaminants are removed from entrained air before returning the air to the cabin. Next, the water is pumped through the Particulate Filter ORU followed by two Multifiltration (MF) Beds where inorganic and non-volatile organic contaminants are removed. Once breakthrough of the first bed is detected, the second bed is relocated into the first bed position, and a new second bed is installed. The Sensor ORU located between the two MF beds helps to determine when the first bed is saturated based on conductivity. Following the MF Beds, the process water stream enters the Catalytic Reactor ORU, where low molecular weight organics not removed by the adsorption process are oxidized in the presence of oxygen, elevated temperature, and a catalyst. A regenerative heat exchanger recovers heat from the catalytic reactor effluent water to make this process more efficient. The Gas Separator ORU removes excess oxygen and gaseous oxidation by-products from the process water and returns it to the cabin. The Reactor Health Sensor ORU monitors the conductivity of the reactor effluent as an indication of whether the organic load coming into the reactor is within the reactor's oxidative capacity. Finally, the Ion Exchange Bed ORU removes dissolved products of oxidation and adds iodine for residual microbial control. The water is subsequently stored in the Water Storage Tank prior to delivery to the ISS potable water bus. The Water Delivery ORU contains a pump and small accumulator tank to deliver potable water on demand to users. The WPA is controlled by a firmware controller that provides the command control, excitation, monitoring, and data downlink for WPA sensors and effectors. 


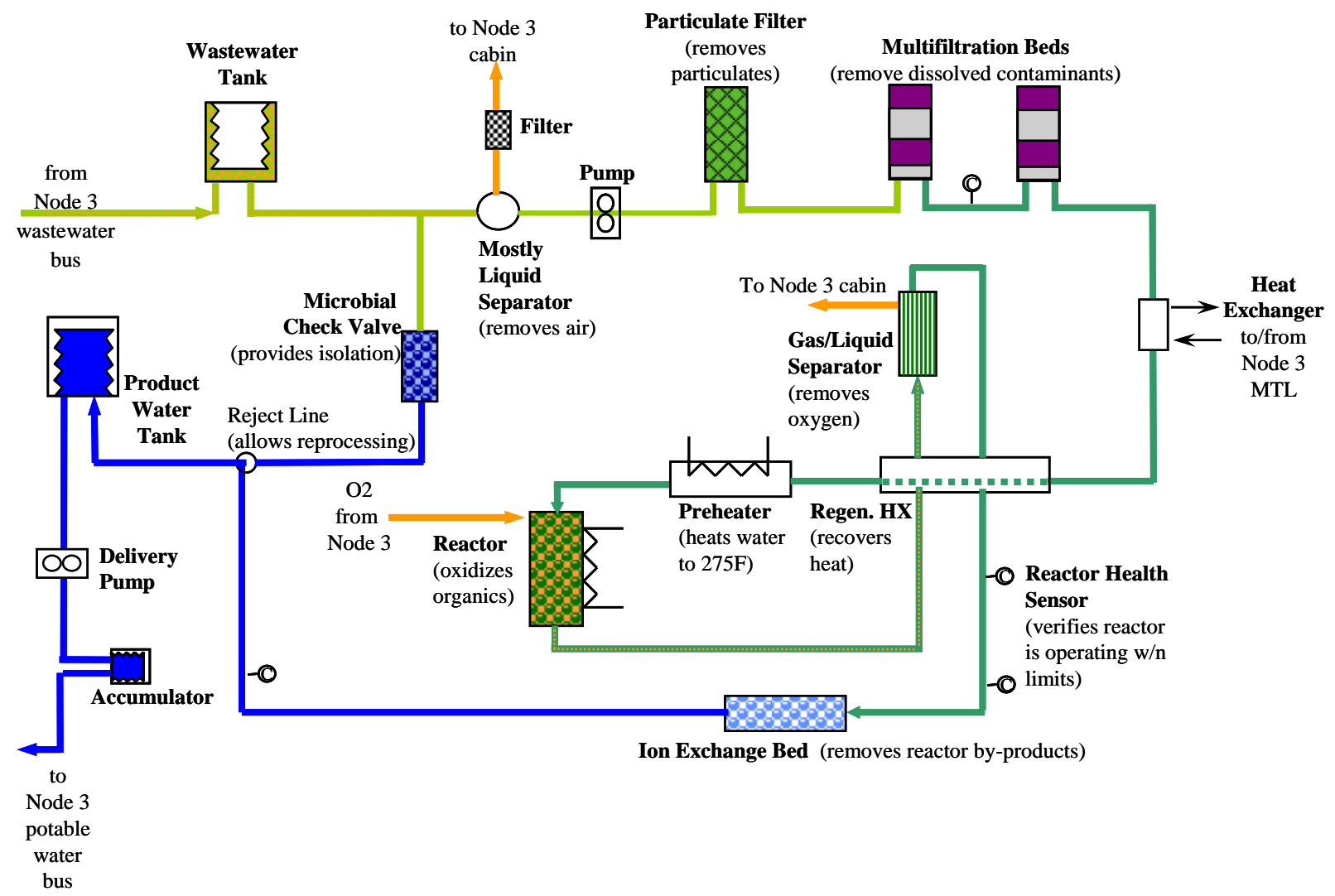

Figure 3. WPA Simplified Schematic

\section{B. Urine Processor Assembly Overview}

A simplified schematic of the UPA is shown in Figure 4. Pretreated urine is delivered to the UPA either from the USOS Waste and Hygiene Compartment (outfitted with a Russian urinal) or via manual transfer from the Russian urine container (called an EDV). In either case, the composition of the pretreated urine is the same, including urine, flush water, and a pretreatment formula containing chromium trioxide and sulfuric acid to control microbial growth and the reaction of urea to ammonia. The urine is temporarily stored in the Wastewater Storage Tank Assembly (WSTA). When a sufficient quantity of feed has been collected in the WSTA, a process cycle is automatically initiated. The Fluids Control and Pump Assembly (FCPA) is a four-tube peristaltic pump that moves urine from the WSTA into the Distillation Assembly (DA), recycles the concentrated waste from the DA into the Recycle Filter Tank Assembly (RFTA) and back to the DA, and pumps product distillate from the DA to the wastewater interface with the WPA. The DA is the heart of the UPA, and consists of a rotating centrifuge where the waste urine stream is evaporated at low pressure. The vapor is compressed and subsequently condensed on the opposite side of the evaporator surface to conserve latent energy. A rotary lobe compressor provides the driving force for the evaporation and compression of water vapor. Waste brine resulting from the distillation process is stored in the RFTA, which has a capacity of approximately $41 \mathrm{~L}$. When the brine is concentrated to the required limit, the RFTA is replaced with an empty RFTA, which allows the process to repeat. The full RFTA was designed to be returned on the Shuttle for refurbishment so it could be returned to ISS for another cycle. However, the RFTA will be replaced in the next year with the Advanced RFTA (ARFTA), which is a bellows tank that can be filled and drained on ISS. The ARFTA capacity is only $22 \mathrm{~L}$, but the capability to fill and drain the ARFTA on ISS avoids the costly resupply penalty associated with launching each RFTA. The Pressure Control and Pump Assembly (PCPA) is another four-tube peristaltic pump which provides for the removal of non-condensable gases and water vapor from the DA. Liquid cooling of the pump housing promotes condensation, thus reducing the required volumetric capacity of the peristaltic pump. Gases and condensed water are pumped to the Separator Plumbing Assembly (SPA), which recovers and returns water from the purge gases to the product water stream. A Firmware Controller 
Assembly (FCA) provides the command control, excitation, monitoring, and data downlink for UPA sensors and effectors.

The UPA was designed to process a nominal load of $9 \mathrm{~kg} /$ day (19.8 lbs/day) of wastewater consisting of urine and flush water. This is the equivalent of a 6-crew load on ISS, though in reality the UPA typically processes only the urine generated in the US Segment. Product water from the UPA has been evaluated on the ground to verify it meets the requirements for conductivity, $\mathrm{pH}$, ammonia, particles, and total organic carbon. The UPA was designed to recover $85 \%$ of the water content from the pretreated urine, though issues with urine quality encountered in 2009 have required the recovery to be dropped to $70 \%$.

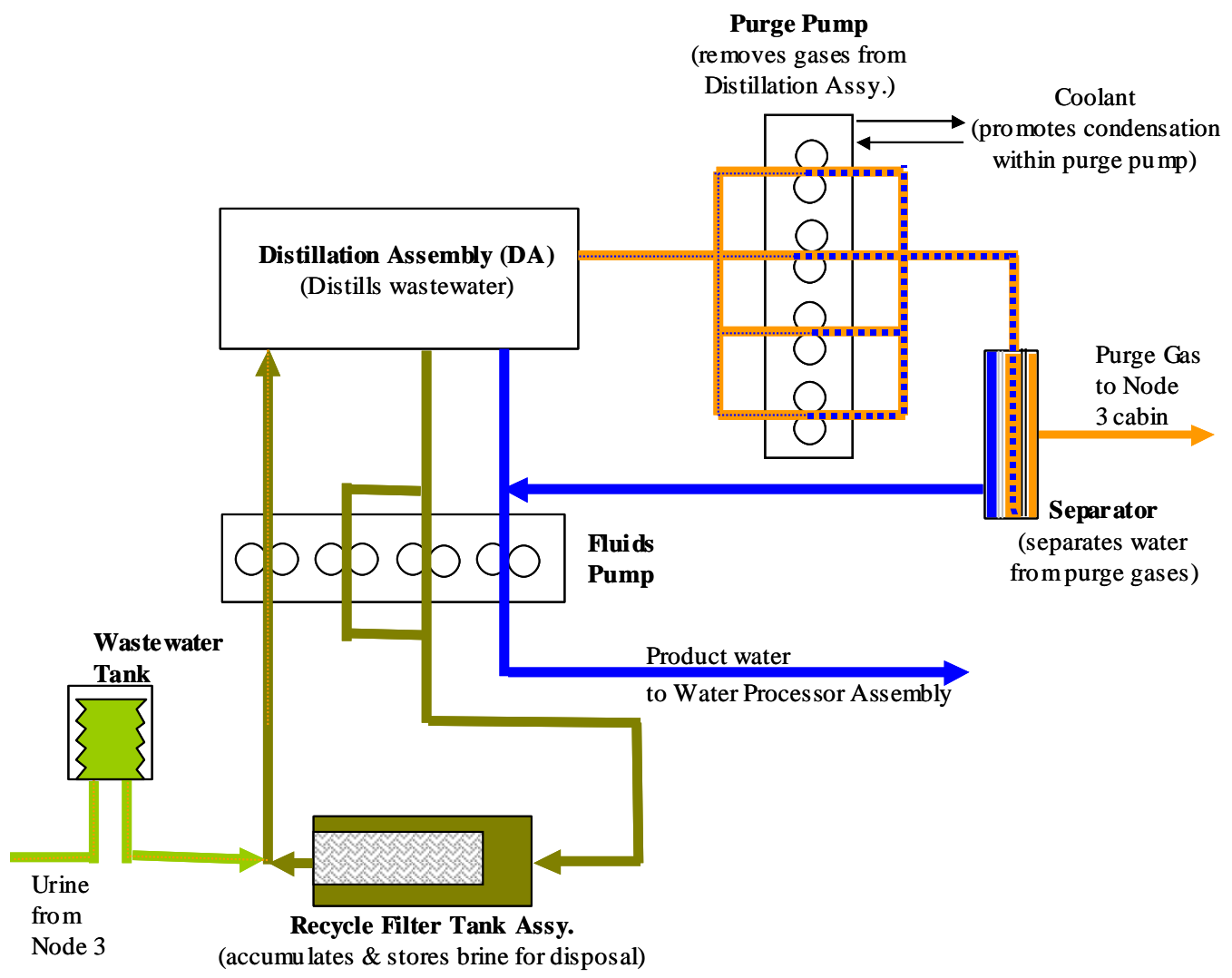

Figure 4. Urine Processor Assembly Schematic

The UPA is packaged into 7 ORUs, which take up slightly more than half of the WRS Rack \#2. The RFTA is the only expendable ORU, sized for a 30-day replacement schedule when processing the daily urine load from 6 crewmembers.

\section{Water Recovery and Management Status}

In the last year, $3480 \mathrm{~L}$ of potable water have been supplied to the US Segment potable bus for crew use and for the OGS. Since the US Segment occasionally produces more water than is used by the crew, periodically excess potable water must be transferred to a CWC-I. A CWC-I is a CWC compatible with the iodine used as a biocide in the US potable water. As described previously ${ }^{1}$, a tee hose and manual shutoff valve were installed on ISS in 2010 to allow potable water to be transferred from a CWC-I back to the WPA Water Storage tank. This capability provided greater operational flexibility for maintaining the ISS water balance in the US Segment. However, in 2011, this capability impacted the potable bus due to the introduction of free gas from CWC-Is.

Free gas is a significant issue in micro-gravity, since it cannot be removed from the water without a gas separator. Since the WPA is designed to deliver water that contains zero free gas, the capability to remove free gas was not developed for the potable bus. Previously, free gas has caused issues on the potable bus when emptying a CWC-I onto the bus. This primarily affected the Potable Water Dispenser (PWD), as free gas would bind up the microbial filter in the PWD and require crew time to vent the gas or replace the filter. In addition, free gas can 
accumulate in the WHC flush water tank. When this free gas is fed to the WHC urinal, instrumentation detects that the pretreatment quality is unacceptable and informs the crew with an LED signal in the WHC rack. As a result, further use of the WHC is halted while the crew clears the free gas. In March 2011, a significant quantity of free gas was inadvertently transferred from a CWC-I to the WPA Storage Tank due to a leaking CWC-I. This occurred due to a $0.033 \mathrm{~cm}(0.013 \mathrm{inch})$ hole in the CWC-I, which was too small to leak water externally and was thus not detected by the crew prior to mating the CWC-I to the tee hose. However, when the CWC-I was emptied of water, free gas was pulled through the hole and into the Water Storage Tank. As a result of this event, several liters of free gas were transferred to the WHC flush tank and urinal operations were significantly impacted. Eventually the flush tank was replaced before nominal operations could be restored. Though most of the free gas was fed to the WHC, the PWD was also impacted when the free gas occluded the microbial filter. However, the crew was able to recover PWD operation by performing multiple dispenses. In response to this issue, a microbial filter was added to the CWC-I transfer operation, between the CWC-I and the tee hose that feeds the Water Storage Tank. This Microbial Removal Filter (MRF) was originally designed to filter microbial contaminants when transferring potable water from CWC-Is. However, the MRF can also address the free gas issue because the 0.2 micron filtration will stop free gas at the available pressure drop. This filter also has a unique design feature, in that it has a vent on the inlet housing that can be used to vent free gas as it accumulates. This allowed the CWC-I transfer operations to be simplified by eliminating the crew effort to degas a CWC-I prior to the transfer, while also insuring no free gas is passed on to the potable bus. To degas a CWC-I, the crew spins the CWC-I to coalesce the gas in one location, and then manipulating the bag to move the free gas to the CWC-I outlet port, where it can be vented into the cabin. Rather than spending up to an hour degassing a CWC-I prior to transfer, the crew theoretically just mates the CWC-I to the MRF inlet, and purges the free gas as it builds up in the housing during the water transfer. Despite this improvement, the MRF is limited. If a significant quantity of free gas is present in the CWC-I, the crew is required to vent the housing multiple times. Onboard execution has found that crew time is minimized by initially removing the bulk of free gas by degassing the CWC-I, and then subsequently using the MRF to transfer water while preventing any free gas from entering the potable bus. Engineering personnel are looking at modifications to this hardware to address this shortcoming.

Finally, the water mass balance in the US Segment has created an issue due to an excess of water. This problem has occurred for several reasons. First, initial projections for WRS reliability were established at $90 \%$ for UPA and WPA. Though these systems have experienced failures, the overall availability has exceeded expectations due to availability of spare ORUs on ISS, as well as on-orbit recovery of operations using the crew to repair hardware. Also, approximately 700 L of potable water was delivered on the last Shuttle (ULF7) in July of 2011, which was not factored into the mass balance projections because of the uncertainty associated with the final Shuttle flight. Finally, the Sabatier has consistently delivered approximately $1 \mathrm{~L} /$ day of water. Since Sabatier is not a baseline system, the planners could not assume it would consistently deliver water. As a result, the US Segment currently has approximately 1700 liters of stored potable water in CWC-Is on ISS. Though this is a positive benefit in terms of supporting various failure scenarios on ISS, it creates stowage problems in the crowded US Segment. Furthermore, CWC-Is are currently only certified to contain potable water for 3 years. After 3 years, if the water has not been removed from the CWC-I, the bag is downgraded to waste water (condensate) grade. To reclaim the water, the crew must transfer the contents of the CWC-I into the WPA Waste Water Tank, where it can be reprocessed to potable water. However, the CWC-I itself is downgraded and its use on ISS is severely limited. To extend the life of these CWC-Is, a shelf life test is being performed on the ground in parallel with ISS operations. During this test, samples are taken every 6 months to certify the CWC-I for a longer storage life. This has been an operational challenge over the last year as shelf life testing to extend the CWC-I certification was ongoing. Numerous CWC-Is would expire under their current certified life, only to be recertified as the shelf life testing results on the ground showed acceptable water quality. These bags became known as "zombie" bags as they would regularly expire, and then return to life based on the shelf life test results. The operations team had a challenge to use these zombie bags during the short window when they were recertified prior to reaching the next expiration date (which would then be extended yet again as testing continued). Due to only so much control over water balance onboard ISS, a number of these bags could not be used and were downgraded. Various solutions are currently being developed to address these issues, including extending the duration of the shelf life test on the ground, returning CWC-Is from ISS on SpaceX and assessing water quality, and developing additional means to transfer water for use in the Russian Segment. 


\section{Urine Processor Assembly Current Status}

The UPA was initially activated on November 20,2008 . In the last year, the UPA has produced 1300 L ( 2870 lb) of distillate at 70\% recovery, cycling through 10 RFTAs and 8 ARFTA cycles during that time. As of June 21, 2012, the total UPA production on ISS is at $4130 \mathrm{~L}(9110 \mathrm{lb})$ of distillate. A graphical summary of UPA production rate and upmass required for ISS operations is provided in Figure 5. The UPA experienced no significant anomalies on ISS in the last year.

As reported previously ${ }^{2}$, Distillation Assembly (DA) S/N 02 failed on October 24, 2009 due to accumulation of solids in the Distillation Assembly. The root cause of the anomaly was due to the precipitation of calcium sulfate in the urine brine at the target recovery of $85 \%$. Calcium is present in the urine primarily due to bone loss from the crew, whereas sulfate is present primarily due to the use of sulfuric acid in the urine pretreatment. Calcium levels on ISS are elevated compared to ground urine due to the absence of gravity. During ground testing, the UPA was proven to have no issues with recovering $85 \%$ of the water from pretreated urine. However, at $85 \%$ recovery on ISS, the higher concentration of calcium resulted in calcium sulfate exceeding its solubility limit. The initial response to this failure was to reduce the recovery to $70 \%$.

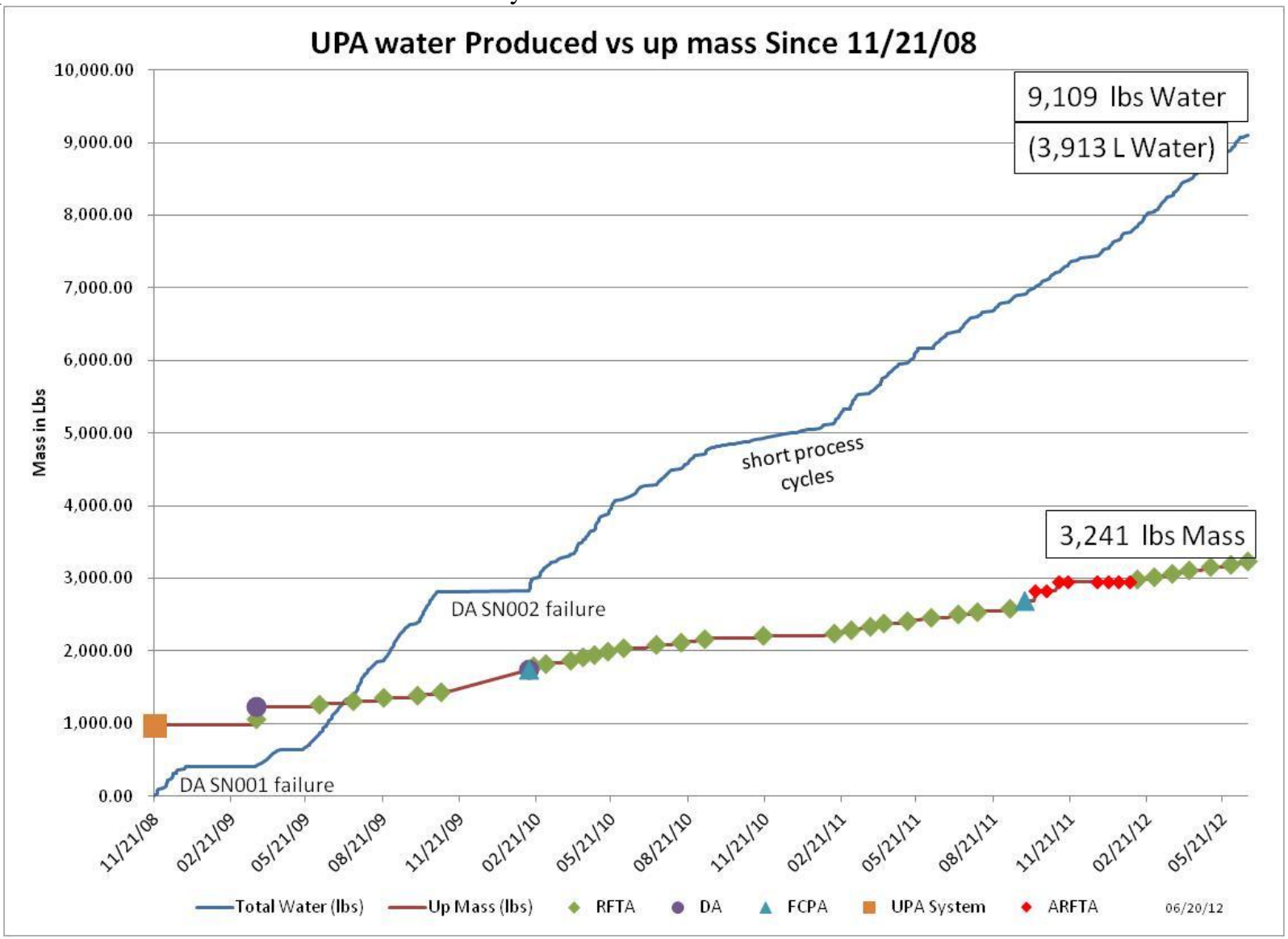

Figure 5. UPA Production and Upmass on ISS

In parallel with this modification to on-orbit operations, NASA personnel have investigated options for returning UPA to $85 \%$ recovery. A significant research effort was performed at JSC to evaluate various technology options, ultimately identifying several viable concepts for achieving $85 \%$ recovery, including ion exchange resin, alternate pretreatment, and a calcium sensor.

Ion Exchange would work by removing calcium from the pretreated urine before it is delivered to the UPA. Calcium is a divalent cation ( +2 charge), and can thus be selectively removed with resin tailored for divalent cations. Though an Ion Exchange Bed will require significant resupply in this application, there is an overall benefit due to the additional water reclaimed by returning UPA to $85 \%$ recovery (which doubles the distillate production). In summary, the current estimate is that $25 \mathrm{~kg}$ /year of resupply would enable the UPA to reclaim an additional 242 $\mathrm{kg} / \mathrm{year}$ of water. Furthermore, another resin has been identified that may allow the annual resupply to be reduced to $14 \mathrm{~kg}$, though this resin is pending further tests to verify its performance. However, the Ion Exchange approach 
adds approximately $3.4 \mathrm{kPa}(0.5 \mathrm{psid})$ of pressure drop between the WHC urinal and the UPA, where limited pressure drop is available to deliver the pretreated urine to the UPA. Engineering personnel are pursuing modifications to the components between the WHC and UPA to insure sufficient pressure drop is available for implementing the Ion Exchange Bed concept.

Engineering and science personnel are also investigating modifications to the pretreatment formula that would eliminate or reduce the sulfate concentration, thus preventing calcium sulfate precipitation ${ }^{5}$. This approach also has significant risk, as the pretreatment formula is critical for maintaining microbial and chemical control in the pretreated urine. The primary objective has been on replacing sulfuric acid while maintaining a $\mathrm{pH}$ of 2.0 in the pretreated urine. Three other acids were tested, including hydrochloric acid, nitric acid, and phosphoric acid. Hydrochloric acid and nitric acid are no longer being pursued because of corrosion concerns and storage hazards. Phosphoric acid is a viable alternative to sulfuric acid, though more acid is required to maintain the desired $\mathrm{pH}$ level. This would require a modification to the Russian pump that adds the pretreatment to the pretreated urine. Scientists at JSC have also investigated reducing the concentration of chromium trioxide to the original dose established by David Putnam ${ }^{6}$. The concentration of chromium trioxide and sulfuric acid has been increased by a factor of 4 in the Russian urinal to address issues with microbial growth observed during ground tests and on the MIR Space Station. However, research at JSC has indicated that the increase in chromium trioxide concentration was not required, and can be returned to its original concentration. These potential changes to the pretreatment will be evaluated in the next year to verify proper microbial and chemical control of the pretreated urine while not causing precipitation of any salts at $85 \%$ recovery in the UPA. Furthermore, materials in the WHC and UPA will be evaluated to verify compatibility with the modified pretreatment.

Finally, another concept under consideration is a sensor that could monitor the calcium concentration in the brine or the pretreated urine as it is delivered to the UPA. If proven reliable, a calcium sensor would allow the UPA to concentrate the urine based on the actual calcium concentration, instead of requiring a conservative \% recovery that accounts for statistical variation in the calcium concentration. This approach would only allow the UPA to achieve approximately $80 \%$ recovery on average, and would therefore only be economically viable if the other approaches cannot be implemented. However, this concept may eventually support $85 \%$ recovery if the ISS medical personnel can develop additional measures (through diet, medication, and exercise routine) to reduce astronaut bone loss.

Since October 2009 (after the failure of DA S/N 02), the UPA has only processed urine collected in the US Segment WHC. This decision was made based on the analysis of pretreated urine collected in the Russian Segment in early 2010. This pretreated urine had an elevated $\mathrm{pH}$ of 2.46 , and also contained non-viable biomass. These observations indicated there may be operational differences with the urinal in the Russian segment that could impact urine quality and subsequently UPA performance. Engineering personnel determined that additional analysis of urine collected in the Russian segment must be performed to provide confidence that the previous result was an aberration. A method was thus developed to sample pretreated urine from the EDVs used to collect urine in the Russian segment. Ten samples were collected and returned to ground for subsequent analysis. A review of this analysis has concluded that the quality of pretreated urine collected in the Russian Segment is statistically no different than that collected in the US Segment. Therefore, engineering personnel have approved processing of Russian urine through the UPA. However, there are no plans to begin this on ISS, due to the issues mentioned previously related to the surplus of water in the US Segment mass balance. Currently, processing urine from the Russian segment would only exacerbate the current problem with excess potable water storage on ISS.

A significant operational change for the UPA in 2011 was the integration of the Advanced RFTA (ARFTA). This hardware replaces the current RFTA with a bellows assembly that can be drained and emptied on ISS. Though ARFTA operation requires more crew time to fill and drain each tank, it provides a significant savings in launch mass (avoiding approximately $200 \mathrm{~kg}$ annually for launching RFTAs). The ARFTA implements a bellows that operates at a slight subambient pressure to support filling the tank from the UPA Waste Tank, which operates at a slight positive pressure. This is similar to the approach used to fill the RFTA, except that the RFTA provides more pressure drop for fluid flow in this configuration because it is launched and delivered to ISS at vacuum pressure. Once the ARFTA tank is full, the UPA completes a nominal concentration cycle, with the exception that the UPA can only process $49 \mathrm{~L}(108 \mathrm{lb})$ of pretreated urine at $70 \%$ recovery due to the reduced operating volume of the ARFTA tank. In contrast, the UPA processes $95 \mathrm{~L}$ for each RFTA at $70 \%$ recovery. When the concentration cycle is complete, the ARFTA tank is removed from the rack. A compressor is then used to pressurize the gas side of the bellows, collapsing the bellows and thus emptying the brine into a Russian EDV, the Progress Rodnik tank, ATV water tanks, or a Temporary Urine Brine Storage System (TUBSS). TUBSS is a collapsible bag currently in development, and will provide ISS with a NASA-provided container for storing pretreated urine or brine. Figure 6 provides a simplified schematic of the drain configuration. Two ARFTA tanks were delivered on Shuttle flight ULF7 for use on ISS. Each tank was cycled 4 times to verify successful operation on ISS. Initial operation on ISS 
was inconsistent, due to differences between the actual versus estimated tank capacity, uncertainty with the quantity of fluid loaded into each tank for launch, and errors associated with filling the tanks on ISS. However, these issues were eventually resolved with additional tank cycles, and sufficient consistency was established over the 4 tank cycles to convince engineering personnel that the tanks could reliably be used for their intended function. Once this effort was complete, the ARFTA tanks were removed from the UPA and the system was reconfigured to use the remaining 8 RFTAs on ISS. The RFTAs require significantly less crew time on ISS compared to the ARFTA, and therefore it is desirable to use the RFTAs already on ISS once the ARFTA checkout was complete. Once these RFTAs are consumed, the UPA will be reconfigured for ARFTA for the remainder of ISS operations.

A final modification to the UPA/ARFTA concept is currently in development. This modification will allow the crew to fill and drain the ARFTA without removing the tank from the rack. This modification is desirable because approximately 45 minutes of crew time is required to removal/install the ARFTA following each concentration cycle. Therefore, this modification would save approximately 12 hours of crew time each year, which is desirable due to the limited crew time available for maintenance tasks on ISS.

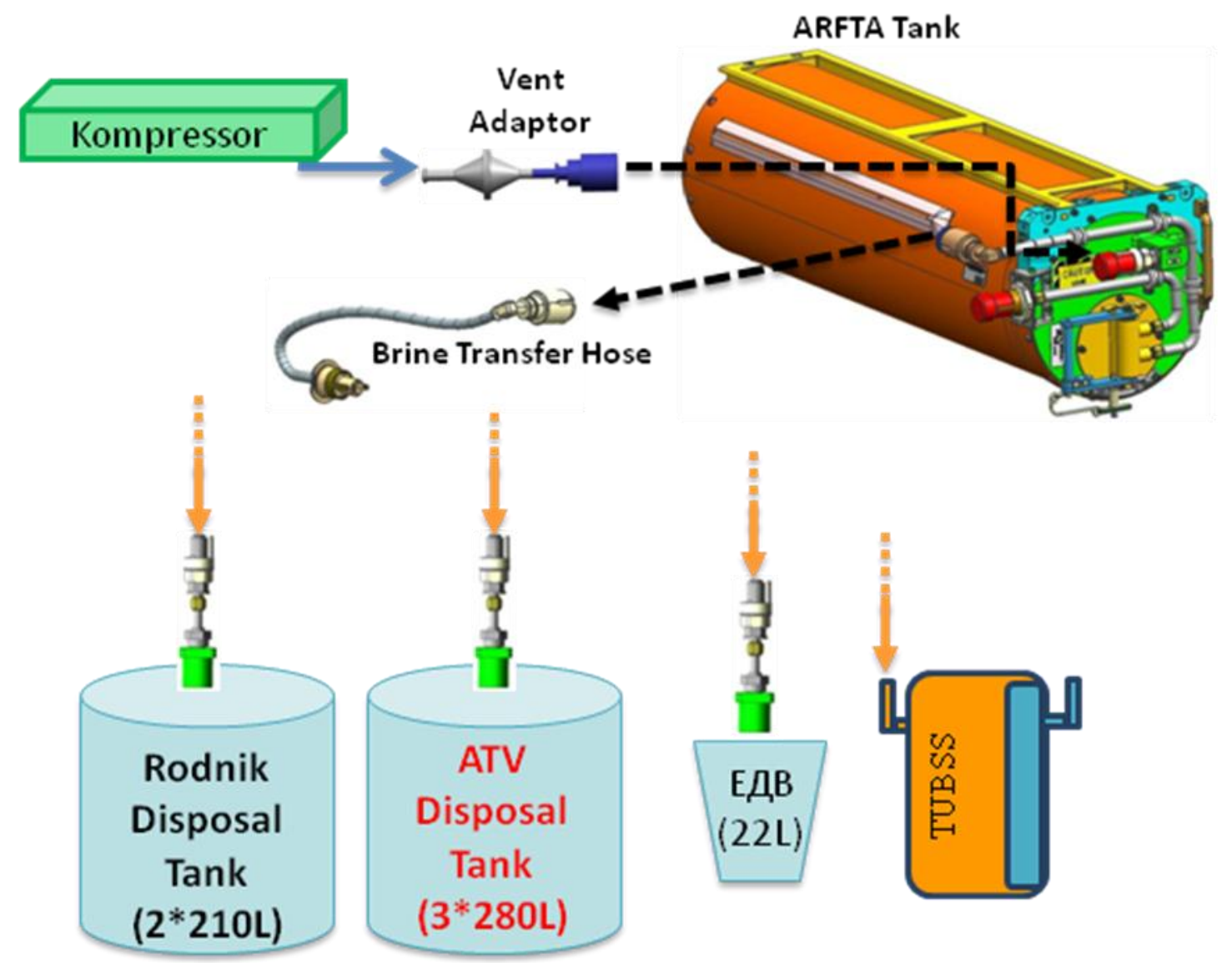

Figure 6. Drain Configuration for the ARFTA Tank

\section{Water Processor Assembly Current Status}

The WPA was initially activated on November 22, 2008. As of June 20, 2012, the WPA has produced approximately $10,640 \mathrm{~kg}(23,470 \mathrm{lb})$ of product water, including $3480 \mathrm{~kg}(7680 \mathrm{lb})$ in the last year.

Three anomalies have occurred to the WPA in the past year on ISS. First, the WPA process pump experienced numerous faults in which the pump appeared to seize, always within the first 25 minutes of a WPA process cycle. Engineering analysis of this anomaly indicated the fault could be due to an obstruction in the pump gears or an intermittent failure of the motor controller. Since the pump was always able to operate after the anomaly, no further troubleshooting was performed on ISS, and eventually the anomalous faults ceased.

Second, the WPA experienced another increasing trend in the Total Organic Carbon (TOC) concentration in early 2012 (see Figure 7), similar to the anomaly observed in $2010^{1,2}$. This trend began after approximately $4200 \mathrm{~L}$ 
of MF Bed throughput, which was also consistent with the trend observed in 2010. Before on-orbit troubleshooting could be pursued, the Catalytic Reactor failed due to a leaking o-ring. This failure had the same root cause as the leak in $2010^{2}$, and was not unexpected after two years of operation on ISS. The current reactor includes new o-rings that are compatible with the operating environment, and are designed to support the 5-year life of this hardware. Along with replacing the reactor, both MF Beds were also replaced to insure the new reactor was not degraded with any organic contaminants. After this maintenance activity, the product water TOC continued to rise, consistent with the trend after replacement of both MF Beds (but not the Catalytic Reactor) in 2010. To provide additional understanding of the root cause for the TOC trend, the Ion Exchange Bed was replaced in April 2012 while the product water TOC was still increasing. Subsequently, the product water TOC returned to nominal levels. Samples were taken of the condensate, waste water, MF Bed effluent (before and after the new MF Beds were installed), and product water for return on the Soyuz and subsequent ground analysis. Analysis of the product water confirmed that the source of the TOC rise is dimethylsilanediol (DMSD), consistent with the TOC trend in 2010. DMSD is a common by-product of the degradation of polydimethylsiloxanes (PDMS), which are common compounds present in various products, including caulks, adhesives, lubricants, and hygiene products. Various PDMS compounds are prevalent on ISS, and analysis of the current and previous condensate samples from ISS also indicates that DMSD has been present in the WPA waste water since WPA operations began on ISS. In addition, $41.9 \mathrm{mg} / \mathrm{L}$ of DMSD was detected in a sample of the MF Bed effluent taken before the beds were replaced on July 29. This result is consistent with the sample of the MF Bed effluent in 2010 prior to bed changeout, in which the DMSD was detected at $37 \mathrm{mg} / \mathrm{L}$. An additional sample of the MF Bed effluent was taken approximately two weeks after replacement of the MF Bed. Analysis of this sample showed no DMSD detected above the detection limit of $0.4 \mathrm{mg} / \mathrm{L}$. This is also consistent with the sample in 2010 taken after MF Bed changeout, in which DMSD was reported as $<0.4 \mathrm{mg} / \mathrm{L}$. These results indicate the MF Beds are initially removing the DMSD, but eventually the DMSD saturates the adsorbent and ion exchange resin in each bed and is in the reactor influent at a concentration of approximately 40 $\mathrm{mg} / \mathrm{L}$. To determine the effect of DMSD on reactor performance, a flight-like reactor is being challenged with the contaminant level expected on ISS (including DMSD). Preliminary results indicate the reactor is consistently removing approximately $70 \%$ of the DMSD, resulting in approximately $10 \mathrm{mg} / \mathrm{L}$ of DMSD in the reactor effluent. If this ground test accurately represents reactor performance on ISS, the DMSD is being initially removed by the Ion Exchange Bed, given the fact that DMSD has a slight ionic charge. Eventually, the Ion Exchange Bed is saturated with the DMSD, which results in a breakthrough curve consistent with the TOC trend observed from the ISS TOC Analyzer (see Figure 7). Additional tests will evaluate this theory by challenging the resin in the Ion Exchange Bed with DMSD, and verifying the TOC trend observed on ISS.

To gain a better understanding of the MF Bed performance on ISS, the MF Bed removed from the first position in 2010 was returned to the ground and analyzed in late 2011. A detailed review of this investigation and results can be found elsewhere ${ }^{7}$. However, a key finding was that several polydimethylsiloxanes (PDMS) had saturated the adsorbent and ion exchange resin. This is inconsistent with the MF Bed design concept, which was to insure that ionic breakthrough of the MF Bed occurred before organics saturated the adsorbents. Unfortunately, the various PDMSs are not effectively removed by the adsorbent, and may therefore be saturating the second MF Bed and subsequently reaching the catalytic reactor. In this scenario, they would degrade reactor performance and result in incomplete oxidation of the volatile load entering the reactor, and subsequently causing the TOC trend shown in Figure 7. Analysis of the second MF Bed will be performed later in 2012 to determine if the PDMSs are actually saturating both beds and therefore entering the reactor on ISS. Based on this analysis and the aforementioned Ion Exchange Bed test with DMSD, engineering personnel will develop a new design of the MF Bed that removes problematic organics and therefore insures effective operation of the Catalytic Reactor. 


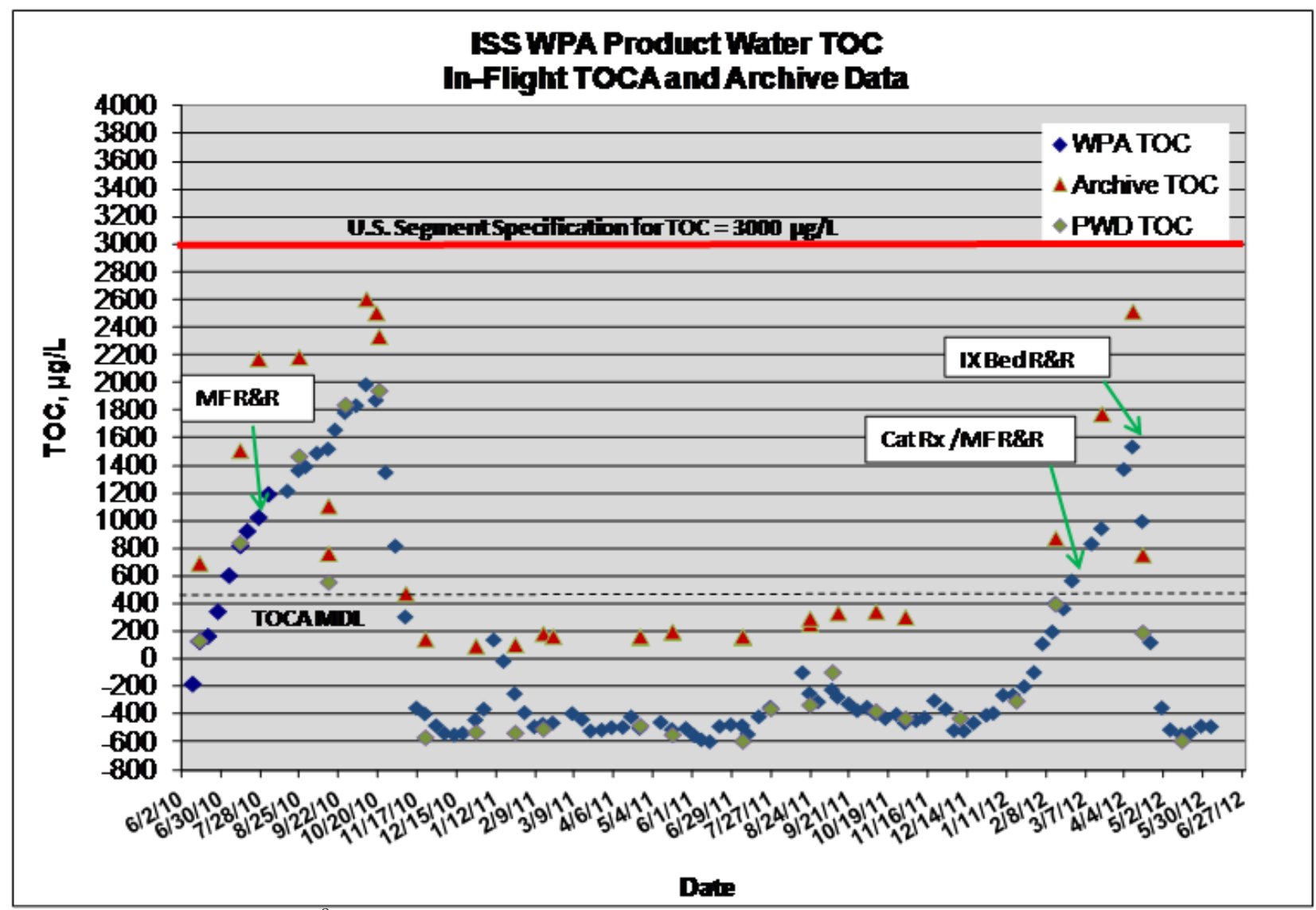

Figure 7. WPA TOC Trend ${ }^{8}$

Previous papers (see Reference 1 and 2) have addressed the issue with increased pressure drop between the waste tank and the Mostly Liquid Separator (MLS). This anomaly occurred due to growth of biomass in the plumbing between the waste tank and the MLS, specifically in the two solenoid valves that have smaller clearances that the rest of the nominal plumbing. In 2010, after the Pump/Separator ORU was replaced, a filter was installed upstream of the MLS's inlet solenoid valve. In March 2011, the Waste Tank solenoid valve and the waste water filter (installed to protect the MLS inlet solenoid valve) both required maintenance. The crew removed the Waste Tank solenoid valve and capped the line (allowing flow through the passageway), and replaced the waste water filter with a new filter. During this time, WPA operations were also modified to control the growth and release of biomass in the waste tank, which is considered to be the primary source of solids contributing to the loading of the waste water filter and solenoid valve. This was primarily accomplished by managing cycles on the waste tank bellows, such that the bellows was cycled over its operating capacity each month to prevent significant accumulation of biomass growth on the bellows. Since March 2011, no significant increase in the pressure drop in this plumbing has been observed. In addition to the tank management scheme, a software modification will be implemented in late 2012 by which the waste water filter and MLS inlet are flushed with iodinated water at the end of each process cycle, providing additional mitigation against biological growth.

The Separator Filter ORU is used to remove aromatic organics from the gas vented by the MLS. This ORU was removed from the WPA in 2011, and returned to the ground for analysis. The purpose of this analysis was to verify the hardware was functioning as designed, and to determine how much capacity was remaining in the adsorbent material. The analysis showed that significant capacity was still available in the adsorbent after almost 2 years of operation on ISS. Based on these results, the current recommendation is to extend the scheduled replacement of this ORU from 1 year to 5 years.

As noted previously, the Multifiltration Beds were replaced in February 2012 as part of the TOC trend investigation. The MF Beds had a total throughput of $4613 \mathrm{~L}$ when they were removed. The Ion Exchange Bed was removed on April 30, 2012, after 3.5 years of use on ISS and a throughput of 9416 L. This bed was initially scheduled for replacement in November 2011 based on the expected life of the MCV resin in the bed effluent, but its life was extended based on ground analysis that showed the MCV resin was still imparting an iodine concentration 
of $2.2 \mathrm{mg} / \mathrm{L}$. At the time this ORU was removed, there were no indications of ionic breakthrough. As of April 2012, there are no indications that the Particulate Filter is loading after approximately 3.5 years of operation on ISS. Similarly, the Gas Separator has shown no indication of performance degradation after 3.5 years of use.

\section{Conclusion}

In the past year, the WRS has continued to provide the ISS crew with potable water for drinking, electrolysis via the Oxygen Generation System, flush water for the Waste \& Hygiene Compartment, and hygiene water. The UPA has operated nominally in the past year, though at a reduced water recovery of $70 \%$ to prevent precipitation of calcium sulfate in the brine. Though progress has been made toward the goal of returning to $85 \%$ recovery, ongoing technology development will not be ready for implementation on ISS for at least another year. Furthermore, the current water balance on ISS does not require 85\% recovery to meet current ISS needs, due to the reliability of the UPA/WPA and the resupply capability of the Progress, HTV, and ATV vehicles.

The WPA experienced several operational issues in the last year. Several unexplained pump faults occurred in the summer of 2011 that could not be isolated to the pump or motor controller. Since these faults have ceased, the investigation is currently suspended. In early 2012, the WPA product water quality began exhibiting an increasing TOC trend, similar to that observed in 2010. Engineering and science personnel continue to investigate this trend. Finally, the Catalytic Reactor ORU was replaced in February 2012 due to a failed o-ring. This failure was not unexpected, since this ORU also contained the flawed o-rings that contributed to the failure in 2010. The ORU now installed (as well as all subsequent ORUs that will be built) has been modified to address this design issue.

\section{Acknowledgments}

The authors wish to acknowledge the effort of the many engineers at NASA MSFC/JSC, Hamilton Sundstrand, and Boeing that have performed excellent work in the last year toward the operation, troubleshooting, and recovery of the Water Recovery System hardware on ISS.

\section{References}

1. Carter, D.L., N. Orozco, "Status of the Regenerative ECLSS Water Recovery System", AIAA 1021863, presented at the 41" International Conference on Environmental Systems, Portland, Oregon, July, 2011.

2. Carter, D.L., "Status of the Regenerative ECLSS Water Recovery System", AIAA 758248, presented at the $40^{\text {th }}$ International Conference on Environmental Systems, Barcelona, Spain, July, 2010.

3. Carter, D.L., "Status of the Regenerative ECLSS Water Recovery System", SAE 2009-01-2352, presented at the 39" International Conference on Environmental Systems, Savannah, Georgia, July, 2009.

4. Bagdigian, R.M., D.L. Carter, and G. Sitler, "Status of the Regenerative ECLSS Water Recovery System", SAE 2008-012133, presented at the $38^{\text {th }}$ International Conference on Environmental Systems, San Francisco, California, July, 2008.

5. Muirhead, Dean, Evaluation of Alternative Pretreatment Formulations for Minimizing the Risk of Mineral Precipitation During Distillation of Urine, ESCG-4106-12-CHLSS-DOC-0002, January 2012

6. Putnam, David F., S. Russell, P. Birbara, Recovery of Water from Urine by Chromium Ion Treatment and Distillation, United States Patent 3,556,949, 1971

7. Bowman, B, M. Wilson, H. Cole, N. Orozco, and D.L. Carter, Performance Evaluation of the ISS Water Processor Multifiltration Beds, AIAA 1277990, presented at the $42^{\text {nd }}$ International Conference on Environmental Systems, San Diego, California, July 2012

8. Personal Email Correspondence, J. Straub, Latest TOCA Results, 07 June 2012 